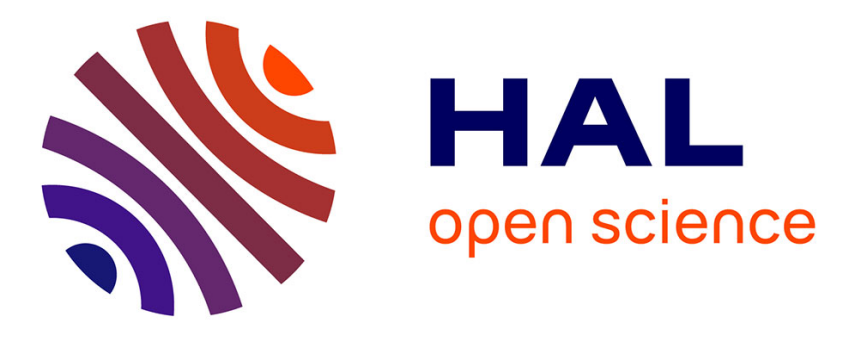

\title{
The third generation of multichannel Raman spectrometers
}

\author{
A. Deffontaine, M. Bridoux, M. Delhaye, E. da Silva, W. Hug
}

\section{To cite this version:}

A. Deffontaine, M. Bridoux, M. Delhaye, E. da Silva, W. Hug. The third generation of multichannel Raman spectrometers. Revue de Physique Appliquée, 1984, 19 (5), pp.415-421. 10.1051/rphysap:01984001905041500 . jpa-00245211

\section{HAL Id: jpa-00245211 https://hal.science/jpa-00245211}

Submitted on 1 Jan 1984

HAL is a multi-disciplinary open access archive for the deposit and dissemination of scientific research documents, whether they are published or not. The documents may come from teaching and research institutions in France or abroad, or from public or private research centers.
L'archive ouverte pluridisciplinaire HAL, est destinée au dépôt et à la diffusion de documents scientifiques de niveau recherche, publiés ou non, émanant des établissements d'enseignement et de recherche français ou étrangers, des laboratoires publics ou privés. 
Classification

Physics Abstracts

$07.65-42.80-32.20 \mathrm{~F}$

\title{
The third generation of multichannel Raman spectrometers
}

\author{
A. Deffontaine, M. Bridoux, M. Delhaye \\ Laboratoire de Spectrochimie Infrarouge et Raman C.N.R.S., \\ Université des Sciences et Techniques de Lille, Bât. C.5, 59655 Villeneuve d'Ascq Cedex, France
}

\section{E. Da Silva}

D.I.L.O.R., 244 ter rue des Bois Blancs, 59000 Lille, France

and W. Hug

Institute of Physical Chemistry, University of Fribourg, CH. 1700 Fribourg, Switzerland

(Reçu le 30 novembre 1983, révisé le 31 janvier 1984, accepté le 3 février 1984)

\begin{abstract}
Résumé. - Cet article décrit un nouveau spectromètre Raman multicanal. Chaque composant de la partie optique (compartiment échantillon, systèmes de positionnement de l'échantillon, filtres, prémonochromateur, spectrographe) a été conçu avec le plus grand soin pour que l'appareil réalisé soit de la meilleure qualité, très fiable et très commode d'emploi. Le système de détection utilise une barrette de photodiodes, l'électronique de lecture et le système d'acquisition de données utilisent des circuits électroniques et logiques développés spécialement pour conduire à une dynamique élevée et un bruit faible. Les tests montrent qu'on peut enregistrer avec ce nouvel instrument des spectres Raman de qualité comparable à ceux enregistrés à l'aide d'un spectromètre Raman monocanal conventionnel tandis que le temps d'acquisition est très notablement réduit.
\end{abstract}

\begin{abstract}
A new multichannel Raman spectrometer is described. Each component of the optical part (sample compartment, sample adjustment provisions, filters, fore-monochromator, spectrograph) have been carefully designed to build a high quality, high reliability and easy to use instrument. The detection system uses a selfscanned photodiode array and the read-out electronics and data acquisition system are based on electronic circuits and logics specially developed to give a high dynamic range with low noise. Tests show that the Raman spectra recorded with this new instrument are of quality comparable to that obtained from a conventional single channel Raman spectrometer while the time required to acquire a spectrum is greatly reduced.
\end{abstract}

\section{Introduction.}

1.1 Historical AND general Remarks. - Molecular spectroscopy is one of the most powerful tools in analytical chemistry. Raman spectroscopy in particular is a technique with an analytical potential unique in many respects, but experimental difficulties, to a large extent associated with the small scattering cross-sections of the spontaneous Raman effect, have severely limited its acceptance by analytical laboratories in the past.

At present, the single channel recording is still the standard method to obtain Raman spectra. Typically photons are detected in a spectral band pass of 1 to $10 \mathrm{~cm}^{-1}$ with a mechanical scanning system which allows the successive analysis of the spectral elements of interest. The multichannel technique in contrast enables one to simultaneously record a large number of spectral elements, typically composing a range of about $1000 \mathrm{~cm}^{-1}$, with a sensitivity per channel comparable to that of a photomultiplier. This results, of course, in a drastic reduction of the time required to obtain Raman data and, perhaps less obvious, also in a decrease of the noise because multichannel detection reduces the effect of fluctuations in the intensity of the exciting light, of variations in the sample due to dust and thermal Schlieren (optical disturbances due to variations of the index of refraction), and of changes in the fluorescent background often present in Stokes Raman spectroscopy. 
The first generation of multichannel Raman spectrometers used photographic plates as detective material and had a comparatively low sensitivity. A second generation of instruments, developed over the past two decades [1], relied on image intensifiers and low light level television cameras. The main drawbacks of this type of composite detective arrangement, which excluded its use in general purpose Raman spectroscopy, are low geometric stability and low stability of the sensitivity, distortion of the image, a rather limited resolution, a low dynamic range, readout lag, blooming, and a high sensitivity towards overload.

The advent of solid state self-scanned diode arrays (SSA's) with a sufficient height especially designed for spectroscopic applications, the development of appropriate low noise read-out and signal processing electronics and the design of a dispersive system especially adapted to the requirements of low light level spectroscopy has led to a new generation of multichannel instruments largely devoid of the drawbacks of the earlier ones.

1.2 LAY-OUt OF THE INSTRUMENT. - The block diagram of the multichannel Raman set-up is shown in figure 1.

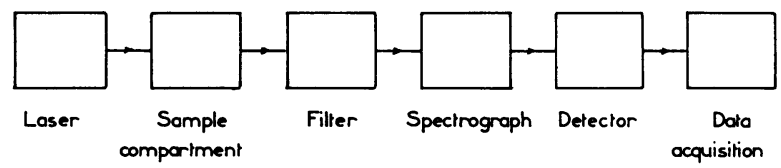

Fig. 1. - Block diagram of a multichannel Raman set-up.

The laser (C. W. or pulsed) excites the Raman spectrum and the scattered light from the sample is filtered, analysed and detected by the Raman spectrometer. We shall discuss first the function of the different elements of the spectrometer.

The instrument must be able to work in very different situations depending mainly upon the nature of the sample. One of the major problems in multichannel Raman spectroscopy is stray light, and it is well known that multichannel instruments so far had only a low stray light rejection (the stray light level in a spectral element is roughly proportional to the product of the areas of the slits, and in a multichannel instrument the "exit slit " is as wide as the spectral image). While a single spectrograph can be used for Raman spectroscopy of gases or neat liquids, it is generally necessary to use band-pass filters to avoid stray light in more demanding applications.

The instrument presents two options in this respect :

- a set of coloured high-pass filters

- a zero-dispersion foremonochromator.

The first solution is only adequate for Raman lines with a sufficient distance from the exciting laser line. On the other side such filters are cheap, available for all usual laser lines and incur little loss in transmission.

The second solution is more elaborate and allows the recording of Raman spectra of solids down to very low frequency Raman lines. In addition the foremonochromator can function as a scanning double grating spectrometer, as is described in section 2.5.

\section{Optics.}

2.1 FRONT OPTICS. - The collecting optics, which is in the same horizontal plane as the focusing optics, is composed of a lens $L_{1}$ (Fig. 2) (50 mm focal length, $f / 1.8$ ) with the focal plane located at the sample, and a lens $L_{2}$ (300 mm focal length) which focuses the parallel beam leaving $L_{1}$ either onto the entrance slit of the foremonochromator or directly onto the entrance slit of the spectrograph.

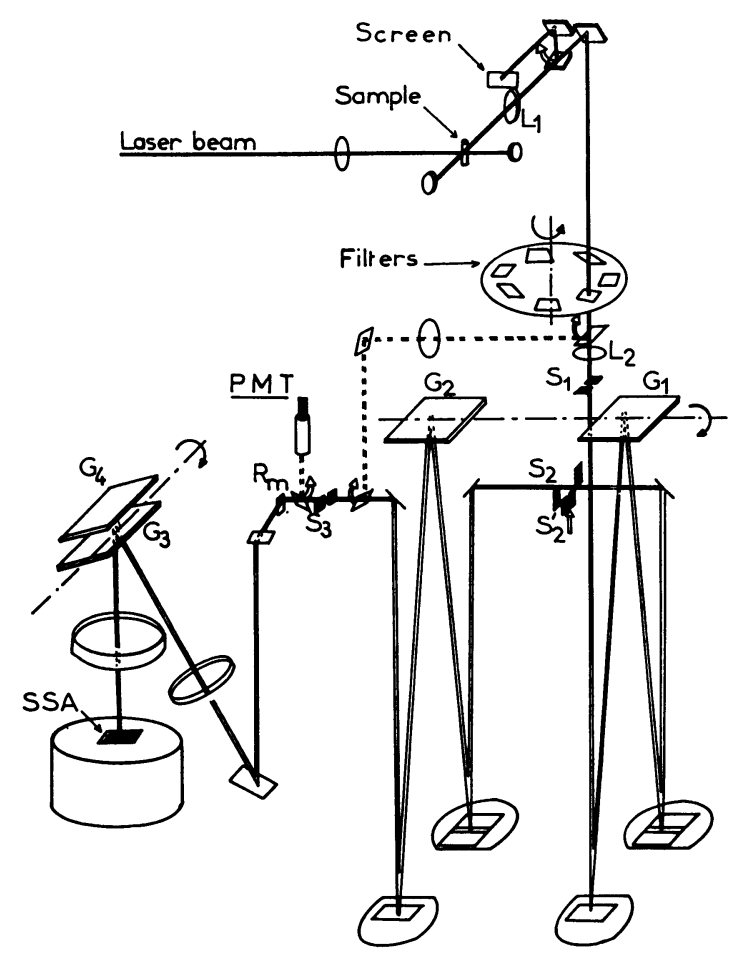

Fig. 2. - Schematic arrangement of the spectrometer.

The magnification at the entrance slit is 6 but can easily be modified by changing $L_{2}$. The position of the front objective $L_{1}$ (focus and axial alignment) can be adjusted with high accuracy by micromotors. A screen permits the visualization of the optical alignment either when the transfer plate is closed for safety reasons or if the sample is inside an oven or a cryostat. The trace of the laser beam through the sample can be observed on this screen which has marks optically aligned with the entrance slit. In addition, a chain of diodes continuously indicates the level of the collected Raman light for a chosen band. This allows an optimization of the optical alignment even for samples which are not transparent. 
Without any modification, it is possible to illuminate the sample from the rear and to collect the backscattered light. In this configuration a removable microprism deflects the laser beam through the front lens $\left(L_{1}\right)$ into the sample, and this same lens collects the scattered light.

2. 2 FORE-MONOCHROMATOR. - It is a zero dispersion, double monochromator which acts as an optical band pass filter by selecting a spectral bandwidth with a high rejection of the other wavelengths (Fig. 2). Two Czerny-Turner monochromators are coupled in such a way that the dispersions substract : the first monochromator splits up the light, the intermediate slit $\left(\mathbf{S}_{2}\right)$ between the two monochromators selects the spectral bandwidth to be analysed, and the second monochromator recombines the different wavelengths and focuses the selected radiations onto the exit slit $S_{3}$. As the two monochromators are identical, the total dispersion is zero. Each monochromator is equipped with a $1800 \mathrm{~g} / \mathrm{mm}$ plane holographic grating $\left(G_{1}, G_{2}\right)$ and two $500 \mathrm{~mm}$ focal length spherical mirrors. The numerical aperture is $F / 10$. The dispersion in the focal plane of the first monochromator is $1.05 \mathrm{~nm} / \mathrm{mm}$. The intermediate slit of $20 \mathrm{~mm}$ width thus selects a $21.0 \mathrm{~nm}$ bandwidth $\left(840 \mathrm{~cm}^{-1}\right.$ near $\left.500 \mathrm{~nm}\right)$. The total transmission efficiency of the foremonochromator is $40 \%$.

The two gratings are mounted on the same axis. Their rotation is achieved by a cosecant arm and adjusts the position of the band pass. The cosecant arm is driven by a screw coupled to a stepping motor. An optical encoder locates the position of the cosecant arm which is related to the wavelength displayed on the spectrometer console. The entrance and the exit slit open symetrically. They are driven by a stepping motor, and their width is also displayed on the console.

2.3 TRANSMiSSION FILTERS. - For work without the foremonochromator a set of mirrors and lenses is automatically placed in position and focuses the scattered light directly on the entrance slit of the spectrograph $\left(\mathrm{S}_{3}\right)$. A rotating plate in the parallel beam between $L_{1}$ and $L_{2}$ can hold seven different colored filters $(50 \mathrm{~mm} \times 50 \mathrm{~mm})$. These high-pass edge filters, accorded with the exciting laser line, are useful to record mid and high frequency Raman lines $\left(\Delta \bar{v}\right.$ a few hundred $\left.\mathrm{cm}^{-1}\right)$ when the spectrograph is employed without foremonochromator. During rotation of the plate, the laser beam is automatically cut off.

2.4 SPECTROGRAPH. - The spectrograph is a conventional design with a plane grating and two lenses. In fact, two readily interchangable gratings $\left(G_{3}, G_{4}\right)$ are mounted on the same turret. It is possible to choose gratings with 600 (ruled), 1200 (holographic), or 1800 (holographic) $\mathrm{g} / \mathrm{mm}$. The focal length of the collimating lense is $600 \mathrm{~mm}$, while the focusing of the spectrum is achieved by a $400 \mathrm{~mm}$ focal length lens. The dispersions which can be obtained are summarized in table $\mathrm{I}$. The spectral field which is observed is $25 \mathrm{~mm}$ with the standard detector. The limit of resolution would be affected by coupling an image intensifier to the photodiode array. The loss of resolution depends on the intensifier but an increase of the limit of resolution by a factor 1.5 seems to be a reasonable estimation for standard microchannel plate intensifiers.

The rotation of the grating is achieved by a stepping motor via a cosecant arm. Its position corresponds to the wavelength which together with the wavenumber is displayed on the console.

2.5 MONOCHANNEL OPERATION. - By means of a movable mirror $\left(\mathrm{Rm}_{4}\right)$ the light leaving the foremonochromator can be sent to a photomultiplier tube. It is then possible to either measure the Raman intensity within the whole spectral band-pass selected or, by narrowing the intermediate slit $\left(\mathrm{S}_{2}\right)$ and by turning the gratings, to record a Raman spectrum in the conventional monochannel photon-counting mode. The chart paper speed is automatically coupled to the electronic scanning device. Apart from recording spectra, the monochannel mode is also useful in that it permits a check on the Raman intensity in order to avoid damage to intensified multichannel detectors.

Table I. - Reciprocal linear dispersion $(\Delta \bar{v} / \Delta x)$, observed field and limit of resolution with a standard detector for 3 different gratings.

\begin{tabular}{|c|c|c|c|c|c|c|c|c|c|}
\hline & \multicolumn{3}{|c|}{$1800 \mathrm{~g} / \mathrm{mm}$} & \multicolumn{3}{|c|}{$1200 \mathrm{~g} / \mathrm{mm}$} & \multicolumn{3}{|c|}{$600 \mathrm{~g} / \mathrm{mm}$} \\
\hline$\lambda(\mathrm{nm})$ & $\begin{array}{l}\frac{\Delta \bar{v}}{\Delta x} \\
\left(\mathrm{~cm}^{-1} / \mathrm{mm}\right)\end{array}$ & $\begin{array}{l}\text { Spectral } \\
\text { field } \\
\left(\mathrm{cm}^{-1}\right)\end{array}$ & $\begin{array}{l}\text { Limit of } \\
\text { resolution } \\
\left(\mathrm{cm}^{-1}\right)\end{array}$ & $\begin{array}{l}\frac{\Delta \bar{v}}{\Delta x} \\
\left(\mathrm{~cm}^{-1} / \mathrm{mm}\right)\end{array}$ & $\begin{array}{l}\text { Spectral } \\
\text { field } \\
\left(\mathrm{cm}^{-1}\right)\end{array}$ & $\begin{array}{l}\text { Limit of } \\
\text { resolution } \\
\left(\mathrm{cm}^{-1}\right)\end{array}$ & $\begin{array}{l}\frac{\Delta \bar{\nu}}{\Delta x} \\
\left(\mathrm{~cm}^{-1} / \mathrm{mm}\right)\end{array}$ & $\begin{array}{l}\text { Spectral } \\
\text { field } \\
\left(\mathrm{cm}^{-1)}\right.\end{array}$ & $\begin{array}{l}\text { Limit of } \\
\text { resolution } \\
\left(\mathrm{cm}^{-1)}\right.\end{array}$ \\
\hline 400 & 76 & 1900 & 5.6 & 132 & 3280 & 9.7 & 288 & 7270 & 22 \\
\hline 500 & 42 & 1050 & 3 & 80 & 1960 & 5.8 & 180 & 4546 & 14 \\
\hline 600 & 24 & 600 & 1.8 & 52 & 1280 & 3.8 & 124 & 3040 & 9 \\
\hline 700 & 16 & 326 & 1 & 32 & 850 & 2.5 & 88 & 2200 & 6.5 \\
\hline 800 & 8 & 146 & 0.5 & 24 & 580 & 1.7 & 64 & 1600 & 4.7 \\
\hline 900 & & & & 16 & 400 & 1.2 & 48 & 1260 & 3.7 \\
\hline
\end{tabular}




\section{Detection system}

The detection system falls into two parts, namely the actual detector on one side and the electronics and logics needed to extract the information from the detector and put the data into a form appropriate for inspection and treatment on the other. The standard detector is a RL 1024 SF linear solid state self-scanned diode array (SSA) from Reticon corporation which contains 1024 discrete sensor elements with a $2.5 \mathrm{~mm} \times 0.025 \mathrm{~mm}$ size each. It is in general used without intensification but can also be combined with an image intensifier stage. The signal extraction part is based on electronic circuits and logics developed originally for Raman optical activity work [2] where stability, linearity, and a high dynamic range with low noise without systematic components is of prime importance.

3.1 Read-out eleCtronics. - The spectral information in the form of the intensity of the electromagnetic radiation as a function of the wavelength is imprinted at the exit of the spectrograph onto the detector as a charge pattern in the form of discrete charged capacitors integrated on the LSI chip. Each capacitor is connected to a light sensitive diode, and it is the charge lost during the illumination period, proportional to the number of photons which have fallen onto the diode, and the position of the diode, which represents the spectral information. This information is extracted by sequentially loading the capacitors to the fixed value of $8.8 \times 10^{7}$ electrons which corresponds to $5 \mathrm{~V}$. The loading current for each capacitor gives rise to a voltage pulse which is converted on the detector chip to a constant voltage level about a tenth the height of the loading pulse. Before the following diode is addressed this voltage level is reset to zero.

At first sight, the ideal way to process the type of signal available from the LSI detector chip would appear to be using a gated integrator approach. This route was followed so far in all commercial designs and provides, in principle at least, the advantages of a variable scan rate with an optimized $\mathrm{s} / \mathrm{n}$ ratio at all scanning speeds. It was found [3], however, that down to read-out times of $5 \mu$ s per diode a $\mathrm{s} / \mathrm{n}$ ratio determined essentially by the basic noise generating mechanisms can be achieved by keeping the square signal pulse from the LSI chip short, and by passing it through a Gaussian filter after amplification. The advantage of this approach is that d.c. offsets on the detector chip and in the preamplifiers are eliminated. The signal is sampled in turn for two video lines read in parallel, multiplexed, and fed to a fast 12 bit A/D converter (Fig. 3) with 1 bit set to a charge of 2000 electrons on the diode array.

3.2 Data acquisition. - A single cycle of a data acquisition sequence basically consists of a signal integration period with a signal read-out, and a

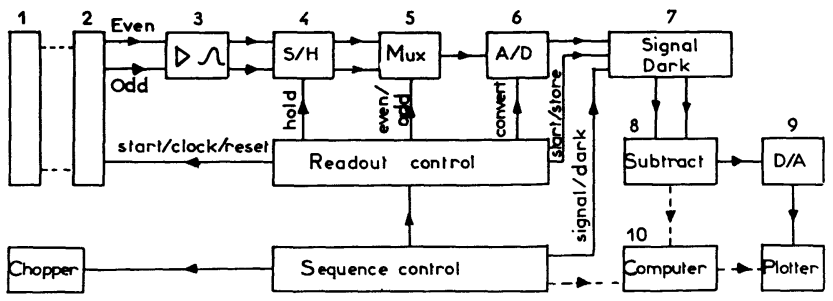

Fig. 3. - Schematic electronic set-up.

1) Image intensifier (optionnal); 2) Detector (Reticon RL 1024 S, SF or RL 5i2 S, SF); 3) Preamplifier and Gaussian filter ; 4) Sample and hold amplifier ; 5) Multiplexer ; 6) Analogue to digital converter; 7) Buffer memory for one signal sweep and one dark sweep; 8) Memory readout and dark sweep substraction unit; 9) Digital to analogue converter : 10) Computer for data acquisition; alternatively, a computer may be connected directly to the A/D converter, see text.

period to integrate and read a dark current offset on the detector equal to the one suffered during the signal integration period. If a $\mathrm{CW}$ laser is used the laser beam is simply chopped off in a down focused region by a blade mounted to the membrane of a small speaker, while for a pulsed laser the signal and dark period are controlled by the firing sequence. The subtraction of the read-out of the dark period from that of the signal period eliminates from the signal, except for the shot noise, the temperature and integration time dependent dark current offset and the fixed pattern baseline signal. The latter represents an integration time independent offset from one diode to another of the order of $1 \%$ of the full scale charge of their capacitors.

From the point of view of the processing of the signal the sequence of the two read-outs, signal and dark, is immaterial provided they are equal is length and provided the temperature of the detector is the same for both in the case where dark current is not negligible. It is therefore entirely possible to store a standard baseline in a computer and to subtract it for each acquisition cycle without actually devoting time to integrate the dark current, or to subtract an appropriately scaled baseline after a certain number of acquisition cycles only. If such a standard baseline has been acquired by many more read-out cycles than the signal itself it may be considered noise free. The implementation of these various options is a matter of the data acquisition software, and the relative merits of the different approaches have been discussed [4].

For the actual processing of the data from the A/D converter there are hardwarewise two different options. There is either the possibility to store the data for each acquisition cycle in a digital buffer memory with $2 \times 1 \mathrm{k} 12$ bit words, or they may be stored directly in the memory of a minicomputer like the HP $1000 \mathrm{~L}$ capable of handling the data from the diode array. The version with the external buffer memory allows the data to be fed at a rate slower than read from the array to any sort of signal averager or computer, or 
they may, by using the built in base line subtraction capability, be displayed in analogous form on an oscilloscope or plotted with a $x / y$ recorder. Real time data acquisition cannot, of course, be achieved in this way, and the experiments have to be done with an appropriate spacing between successive acquisition cycles. In most applications of Raman spectroscopy this presents no problem because the minimum time for an acquisition cycle is constrained by the requirement to accumulate a sufficient number of photons on the detector before read-out, rather than by the data processing electronics.

\subsection{NOISE AND THE NEED FOR INTENSIFICATION. -} The question of where intensification is required, or advisable, and where it is not, can be answered from a comparison of the $s / n$ ratio for a given number of photons of an intensified system with that of a nonintensified array. In a properly designed intensified system with sufficient gain the noise is entirely determined by the intensifier stage. The components are the signal shot noise, the dark current shot noise, and pulse height distribution noise if the intensifier contains a microchannel plate. The noise of the nonintensified array consists likewise of the signal and dark current shot noise, but in addition it contains the read-out noise of the diode array. The total rms read-out noise level achieved by us is below 1000 electrons per scan and diode [5] and is mostly determined by fundamental noise generating mechanisms which are not amenable to a modification.

The read-out noise does not decrease with decreasing signal, and in the non-intensified case and for integrated dark currents below $10^{6}$ electrons it represents the dominant noise component. If the number of the detected photons per individually recorded event and per channel does not exceed a few thousand, intensification therefore is mandatory. For signals above $10^{6}$ detected photons the signal shot noise on the other hand becomes dominant. The relative $s / n$ performance of the intensified and non-intensified system then depends on their quantum efficiencies.

In terms of the number $N_{\mathrm{p}}$ of the photons incident on the detector the point of equal noise performance is given by [4]

$$
N_{\mathrm{p}} \approx 10^{6} /\left(\eta_{\mathrm{S}}^{2} / \eta_{\mathrm{I}}-\eta_{\mathrm{S}}\right)
$$

$\eta_{\mathrm{I}}$ and $\eta_{\mathrm{S}}$ are quantum efficiencies of the photocathode in the intensified design and of the solid state detector alone, respectively. The formula refers to the situation of a noise free base line, negligible dark current, and negligible pulse height distribution noise. Moreover, the throughput is assumed to be independent of using or not using an intensifier stage.

For green light one typically has $\eta_{1} \approx 0.1, \eta_{\mathrm{s}} \approx 0.75$, and therefore $N_{\mathrm{p}} \sim 2 \times 10^{5}$ in the absence of pulse height distribution noise. With pulse height distribution noise, $N_{\mathrm{p}}$ is similarly obtained from the above equation by dividing $\eta_{I}$ through the factor by which the $s / n$ ratio of the intensifier is reduced as compared to the shot noise limited situation. Commonly observed $\mathbf{s} / \mathbf{n}$ degradations are about 2 for modern microchannel plate intensifiers. This yields $N_{\mathrm{p}} \approx 9.5 \times 10^{4}$, a value which is of the same order as the number of photons arriving per second at the detector in a conventional Raman spectrometer for a condensed sample, a Raman band of average intensity, an exciting power of perhaps $100 \mathrm{~mW}$, and a band width of a few $\mathrm{cm}^{-1}$. Thus, due to its high quantum efficiency, the nonintensified solid state detector is competitive with an intensified design well below the limit where shot noise becomes dominant, and for photon numbers which are commonly encountered in Raman spectroscopy.

The value of $9.5 \times 10^{4}$ for $N_{\mathrm{p}}$ corresponds to a charge of approximately $7 \times 10^{4}$ electrons on the diode array, or less than $1 \%$ of the $8 \times 10^{6}$ electron limit of the current 12 bit A/D converter. Discounting aliasing by the A/D converter the ratio of the signal to the rms noise at this point of equal noise performance is of the order of $7 \times 10^{4}\left(\sqrt{7 \times 10^{4}}+1000\right)$ $\approx 55$. If $\mathrm{s} / \mathrm{n}$ ratios below this value are sufficient, working with an image intensifier will be faster, while for higher $\mathbf{s} / \mathbf{n}$ ratios the solid state detector alone is at an advantage. The analysis assumes that the signal is extracted from the array by a single read-out. This represents the most desirable and in the majority of the cases realizable data acquisition mode. For a more general discussion the reader is referred to reference [4].

\section{Performances of the instrument}

Figure 4 to 7 show Raman spectra recorded with our system and are characteristic of its performance without image intensifier.

Figure 4 displays the Raman spectrum of 1, 2, 4 trimethylbenzene excited by the $514.5 \mathrm{~nm} \mathrm{Ar}^{+}$laser line recorded without fore-monochromator and filters for two polarizations ( ${ }^{\|} I_{\perp}$ and ${ }^{\perp} I_{\perp}$ ). The dispersion of the spectrograph with a $1800 \mathrm{~g} / \mathrm{mm}$ grating permits the recording of the entire spectrum $\left(\simeq 3500 \mathrm{~cm}^{-1}\right)$ in three portions (about $1200 \mathrm{~cm}^{-1}$ each in the vicinity of $500 \mathrm{~nm}$ ) with a 1024 element diode array.

Figure 5 shows the Rayleigh and Raman lines (Stokes and Antistokes) of $\mathrm{CCl}_{4}$. The Rayleigh line is not masked and is incident directly onto the diode array. The strongly overexposed diodes are saturated but there is no degradation of the spectrum outside the saturated region. The usable dynamic range is 1 in 4096 and is limited by the 12 bit A/D converter and not by the detector or the read-out electronics [4]. It is important to note that contrarily to other multichannel detectors (e.g. image intensifiers and vidicons), the SSA suffers neither from lag nor blooming and is impervious towards overexposition.

Figure 6 illustrates the high sensitivity of the spectrometer without image intensifier. The Raman spec- 

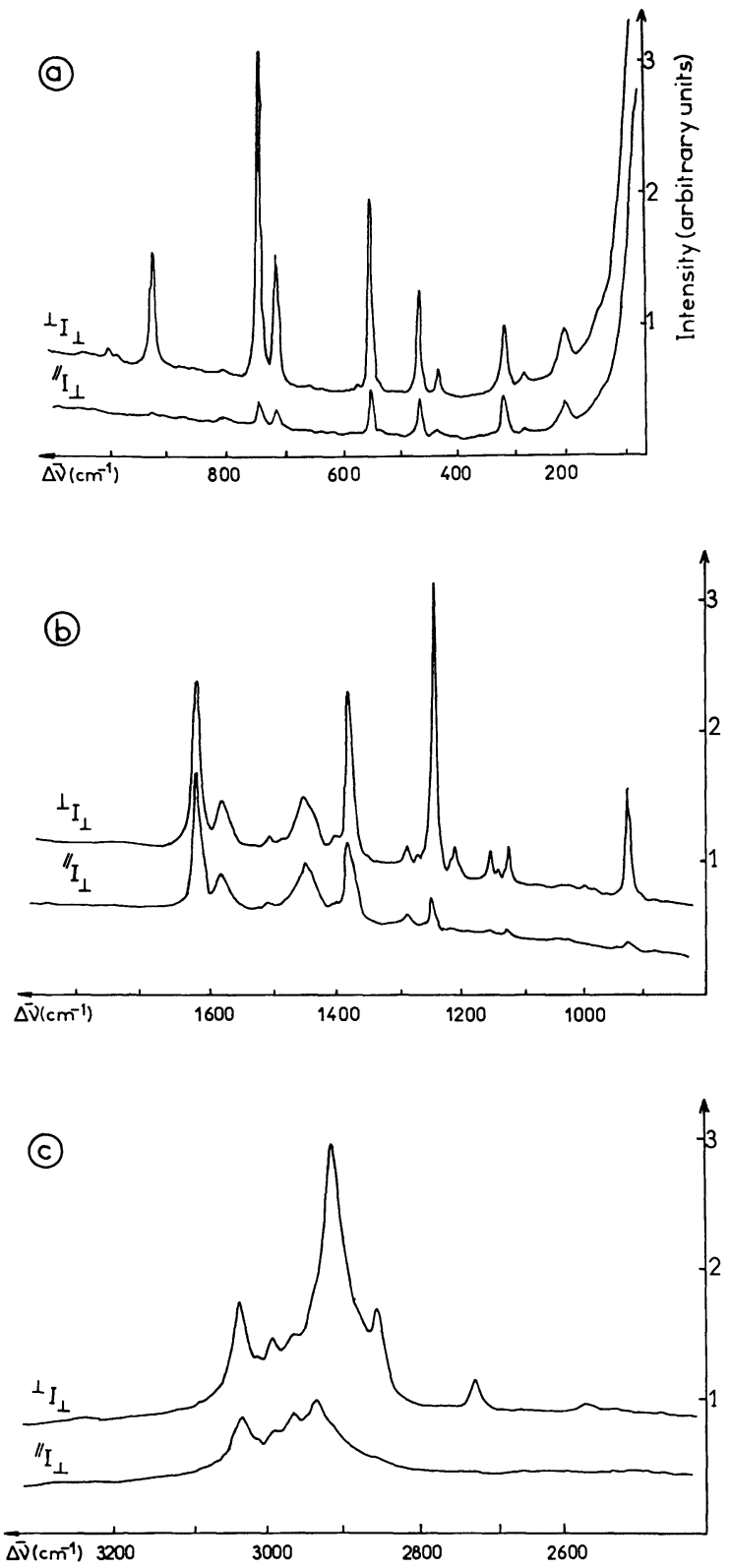

Fig. 4. - Polarized and depolarized Raman spectra of 1, 2, 4 trimethylbenzene excited by the $514.5 \mathrm{~nm}$ line of an $\mathrm{Ar}^{+}$laser $(1 \mathrm{~W})$. The integration time on the detector is $5 \mathrm{~s}$. a, b, c, refer to 3 spectral regions.

trum of gazeous $\mathrm{CO}_{2}$ at atmospheric pressure has been recorded with only $50 \mathrm{~J}$ of laser energy.

Figure 7 shows the low frequency Raman spectrum of $\mathrm{Bi}_{2} \mathrm{O}_{3}$ in powdered form recorded with foremonochromator. This demonstrates the excellent stray-light rejection even in cases where the reflection of the laser light itself is superposed on Rayleigh and Tyndall scattering.

\section{Conclusions.}

The availability of photodiode arrays especially designed for spectroscopic applications has led to the development of a new generation of multichannel

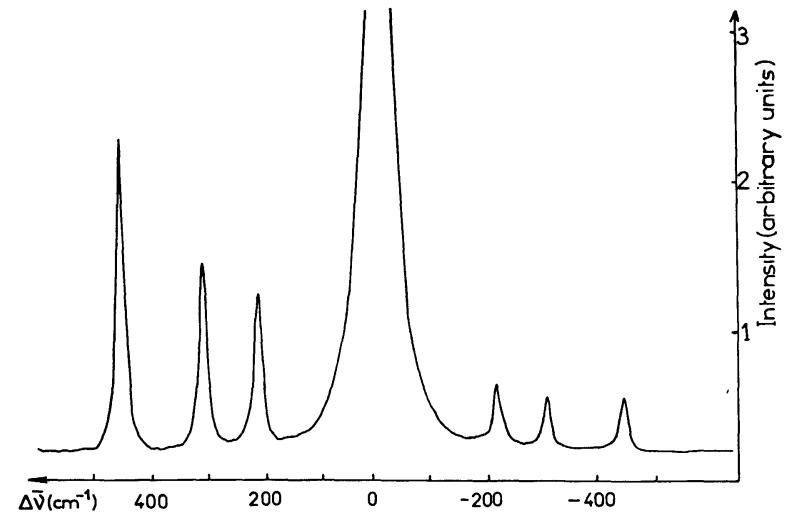

Fig. 5. - Rayleigh and Raman lines of $\mathrm{CCl}_{4}$ (same experimental conditions as for Fig. 4).

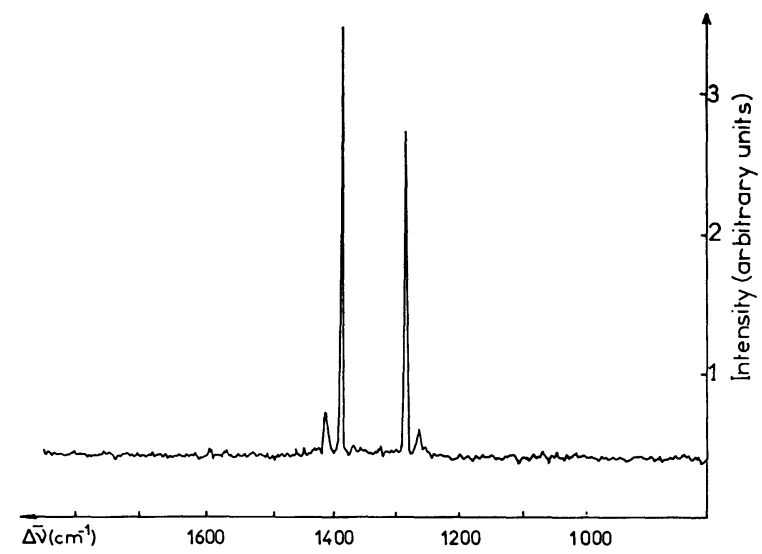

Fig. 6. - Raman spectrum of $\mathrm{CO}_{2}(P=1$ atm $)$ excited by the $514.5 \mathrm{~nm}$ line of an $\mathrm{Ar}^{+}$laser $(1 \mathrm{~W})$. The integration time is $50 \mathrm{~s}$.

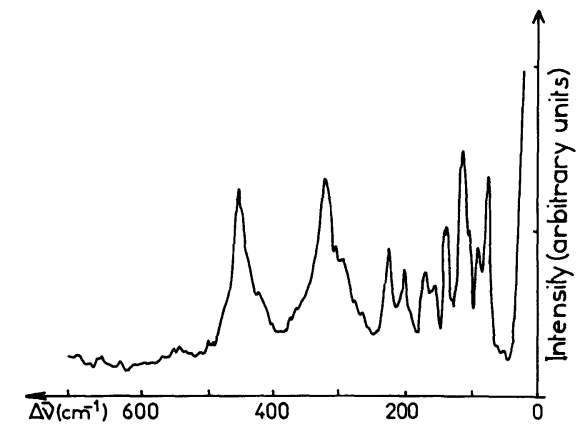

Fig. 7. - Low frequency Raman spectra of powdered $\mathrm{Bi}_{2} \mathrm{O}_{3}\left(\lambda_{\text {exc }}=514.5 \mathrm{~nm}, 25 \mathrm{~mW}\right.$, integration time $\left.1 \mathrm{~s}\right)$.

Raman spectrometers. A particular effort has been made to design a high quality, high reliability and easy to use instrument. All capabilities of the more sophisticated monochannel spectrometers have moreover been retained.

It appears worthwhile to point out that the present instrument can also be used to investigate microsamples by substituting a microscope for the standard 
sample compartment. This enables the recording of Raman spectra of micrometersized particles while maintaining the instrument's specification.

Another important field of application of multichannel instruments is time-resolved Raman spectroscopy which is rapidly becoming an attractive tool for studying chemical and biochemical reactions [6]. For this kind of experiment a pulsed laser is generally required. Sometimes spectra obtained by a single laser pulse are of great interest, and if the signals are weak the detectivity of the photodiodes may not be sufficient. It is then necessary to put an image intensifier ahead of the photodiode array to enhance the sensitivity, e.g. of the microchannel plate variety and coupled directly by optical fibres to the diode array. Such an arrangement provides the advantage of being gatable in the $10 \mathrm{~ns}$ range while having a gain sufficient to detect single photoelectrons.

\section{References}

[1] Bridoux, M., C.R. Heb. Séan. Acad. Sci. 258 (1964) 5620.

Bridoux, M., Delhaye, M., Nouv. Rev. Optique 1 (1970) 23.

Bridoux, M., Deffontaine, A., Delhaye, M., Grase, F., Reiss, C., Proc. 5th ICORS, E. D. Schmid, J. Brandmüller, W. Kiefer, B. Schrader, H. W. Schrötter eds (H. F. Schulz Verlag Freiburg im Breigau) 1976, p. 760.

[2] Hug, W. and Surbeck, H., Chem. Phys. Lett. 60 (1979) 186.

Hug, W., Appl. Spectros. 35 (1981) 115.
[3] Hug, W. and SurbeCK, H., unpublished results.

[4] Hug, W. and Surbeck, H., J. Raman Spectrosc. 13 (1982) 1.

[5] Surbeck, H., Hug, W., Gremaud, M., Bridoux, M., Deffontaine, A. and Da Silva, E., Opt. Commun. 38 (1981) 57.

[6] Bridoux, M., Delhaye, M., Advances in infrared and Raman Spectroscopy, vol. 2, RJH Clark and R. E. Hester, eds (Heyden, London) 1976.

Atkinson, G. H., I.R.S. vol. 10 (Heyden, London) 1982. 